\title{
SPECIES DISTRIBUTION MODELLING OF TWO SYMPATRIC HORNBILLS: THE GREAT HORNBILL AND RUFOUS-NECKED HORNBILL IN BHUTAN
}

\author{
Nir Puri ${ }^{1}$, Amit Verma ${ }^{1}$, Ramesh Chhetri ${ }^{2}$, Harish Chand ${ }^{1}$, and Sandip Rijal ${ }^{1}$ \\ ${ }^{1}$ Forest Research Institute Dehradun \\ ${ }^{2}$ Kali Gandaki Polytechnic Institute, CTEVT, Ghiring 1, Tanahun, Gandaki Pradesh, \\ Nepal
}

January 19, 2022

\begin{abstract}
The Great hornbill (Buceros bicornis) and Rufous-necked Hornbill (Acerosnepalensis) are listed as vulnerable under the International Union for Conservation of Nature Red List of threatened species due to the rapid decline of their population in the world. This research focuses on analysing the habitat suitability of these two important birdspecies across Bhutan. A total of 51 presence locations were recorded from the field survey. The models were simulated using three topographic variables and 19 bioclimatic variables. MaxEnt modelling technique was used for delineating the distribution potential habitat suitability map. The habitat suitability analysis for Great hornbill and Rufous-necked hornbill shows that $2 \%$ and $3 \%$ of Bhutan's total geographical area were highly suitable, respectively. The approach of this study will be beneficial in identifying suitable areas and aiddecision-makers in management and conservation of these vulnerable bird species.
\end{abstract}

\section{Introduction}

Species distribution modelling (SDM) are widely used methodology that has been used to predict the distribution of species on any geographical range (Beale and Lennon, 2012). These are also known as bioclimatic models envelope models and ecological niche models (Araújo and Peterson, 2012). The Maximum Entropy (MaxEnt) model predicts the potential habitat considering entropy of different variables associated with present location of species (Singh et al., 2020). SDM is one of the most active areas of global ecology and many papers has been published around the world to date (Booth, 2018). These are models that use species environment relationships to explain and predict distributions of species(Hao et al., 2019). They rely on statistical correlations between existing species distributions and environmental variable ( $\mathrm{Li}$ and wang, 2013).

Hornbills are recognized as one of the most important bird species in the tropical and subtropical forest of Asia and Africa (Sun et al., 2019). Hornbills are large birds belonging to the Bucerotidae family and out of the 59 extant species of hornbills, 31 are found in Asia(Franco and Minggu, 2019). Hornbills are often called as "Farmers of the forest in terms of their habitat, food, nest-site and seed dispersers (Sherub and Tshering, 2019). They are known as good indicators of the health of forests(Sherub and Singh, 2020). The unique breeding biology of these birds means that they are dependent on big trees of primary forest(Ouithavon et al., 2005).

Hornbills are distributed throughout forested areas of the country (Chaisuriyanun et al., 2011). Bhutan provides a safe home for four hornbill species; Wreathed hornbill Aceros undulates, Oriental Pied hornbill $A n$ thracoceros albirostris , Rufous-necked hornbillAceros nipalensis, and Great Hornbill Buceros bicornis (Nepal, 
2020). Asian hornbills are hunted for their body parts (Casque and tail feathers for traditional attire), for the consumption of their meat, and for their body fat, which is believed to have medicinal properties(Aiyadurai et al., 2010;Bennett et al., 1997). Its population is declining in an alarming rate due to continue habitat fragmentation and degradation, deforestation, logging, and increase in hunting pressure (Pawar et al., 2021). Today only a third of their natural habitat remains a large proportion of it in a fragmented state and with extraordinarily high levels of threats to their persistence (Laurance, 1999). The target species Rufousnecked hornbill has been reported to be extinct in Nepal and close to extinction in Vietnam(Poonswad et al., 2013)(Shukla et al., 2016). To date, no study has been carried out to know regarding hornbill's habitat suitability and distribution in Bhutan. Against backdrop, this study is intended to fill the existing gap with the objective to delineate the potential habitat suitability and identify critical variables associated with Rufous-necked hornbill and Great hornbill in Bhutan.

\section{Material and methods}

\section{Study area}

Bhutan is a small landlocked country spreading over an area of 38,394 Sq. Km (Fig.1) and extending between latitudes $27^{\circ} 31^{\prime} 53.11^{\prime \prime} \mathrm{N}$ and longitudes $90^{\circ} 26^{\prime} 9.07^{\prime \prime} \mathrm{E}$ in the Eastern Himalayas which is bordered by China and India. The annual temperature ranges between $10 * \mathrm{C}$ and $24{ }^{*} \mathrm{C}$ and annual precipitation between $300 \mathrm{~m}$ and $6000 \mathrm{~m}$ across Bhutan (Penjor et al., 2021). The territory of Bhutan is the home for 5500 species of vascular plants, 46 varieties of rhododendrons, 400 type of lichens, 430 varieties of orchids, and 200 types of forest mushrooms (Efremov, 2019). The population is 735,553 of which $62.2 \%$ lives in rural areas, and their livelihoods depend on agriculture and livestock farming(Namgyal et al., 2021). Additionally, more than 95 $\%$ of Bhutan remains vegetated, of which approximately $70 \%$ constitutes natural forest cover(Rajaratnam et al., 2016). The bird species of the country stands at 748 species of which 31 are globally threatened and 18 are part of the 37 endemic bird species which makes stronghold of bird diversity (Norbu et al., 2021). The protected areas system of Bhutan comprises five national parks, four wildlife sanctuaries, and one strict nature reserve(Tshewang et al., 2018).

Figure 1: Location map of the study area with occurrence location of species

\section{Methods}

Figure 2: Flow chart of the methodology outline

The methodology outline is shown in the fig. 2. A total of 56 occurrences points of two sympatric hornbills i.e Great hornbill $(\mathrm{n}=31)$ and Rufous-necked hornbill $(\mathrm{n}=25)$ were collected from the field survey. The field survey was conducted for four months (December 2018 - March 2019). During the field survey, wherever we have sighted hornbills, we took the photo, communicating with local villagers and recorded GPS coordinates (latitude and longitude) along with the elevation. After the field survey, we used 21 environmental variables (BIO_1 to BIO_19, Mean actual Evapotranspiration (AET), and Global Aridity Index (AI) (www.worldclim.org) were downloaded from WorldClim dataset at a resolution of $1 \mathrm{~km}^{2}$. Topograhic variables namely-elevation, aspect, and slope were derived from digital elevation model of Shuttle Radar Topographic Mission (SRTM) having the resolution of $30 \mathrm{~m}$.

A test of auto-correlation was done using DIVA-GIS to remove correlated sites. After the test, 51 presence location are retained and 5 auto-corrrelated points were discarded( 2 presence location for great hornbill and 3 presence location for Rufous-necked hornbill. Likewise, correlation test of 24 variable layers was conducted using the ENM Tools version 1.3(Warren et al., 2010) to test multi co-linearity between predictor variables. . The criteria adopted to predict multicollinearity between the variables was Pearson's correlation coefficients $(\mathrm{r})$. Pearson's correlation coefficient $(\mathrm{r})$ is a measure of the strength of the association between the two variables. After running the correlation test, variables with correlation coeffecient value higher than 0.75 were discarded from the further analysis. Bio_1, Bio_2, Bio_4, Bio_5, Bio_6, Bio_7, Bio_8, Bio_9, Bio_11, Bio_12, and Bio_19 were removed and rest 13 variables were only used for generating the model. To generate the habitat suitability map, all the remaining variables were first converted to ASCII layer to feed into the 
MaxEnt 3.4.1. The model was iterated 100 times with 20 replication using the bootstrap to avoid any biases or extreme value that may arise and output was acheived as the mean among them. All rest of the settings we kept as default in the MaxEnt. The MaxEnt output of ASCII format are converted to raster and later categorized in ArcGIS for further evaluation.

The suitability map obtained will have the value between $0-1$ where 0 represents least suitable and 1 represents most suitable habitat for the species. The maps were further classified into 4 categories: most suitable (0.6-1), moderately suitable (0.4-0.6), marginally suitable (0.2-0.4) and least suitable (0-0.2) (Lu et al., 2012).

\section{Results}

Potential suitable Habitat analysis of Great hornbill (GH) and Rufous-necked hornbill (RNH): The habitat suitability map of GH and RNH is divided into four classes as highly suitable, moderately suitable, and marginally suitable and least suitable. Each following classes are indicated by red, yellow, blue and green, respectively. The MaxEnt result showed that the area wise class percentage analysis for GH comprised of $2 \%, 8 \%, 10 \%$ and $80 \%$ (fig.3; i, ii) whereas RNH comprised $3 \%, 6 \%, 15 \%$ and $76 \%$ (Fig. 3; iv, v) representing highly suitable, moderately suitable, marginally suitable and least suitable respectively. The predictor variables performance with the highest percentage contribution and permutation importance in predicting the species presence location for GH were Elevation, Bio_13-Precipitation of Wettest Month, and Aridity index (Fig. 3; iii) whereas variables: Precipitation of Wettest Month (Bio_13) with 44.7 aspect, and Aridity Index (Fig. 3; vi) are major controlling distribution of RNH.

Figure 3: Habitat suitability map of $\mathrm{GH}$ and RNH with percentage of area suitability for species and permutation importance of of contributing variables

The curves below in figure 4 illustrates how the logistic prediction changes as each environmental variable are varied while keeping all other environmental variables at their average sample value. Red lines are the mean response of the 100 replicates and blue is the +- one standard Deviation. The $\mathrm{X}$-axis represents the ranges of values of the environmental variables whereas $\mathrm{Y}$-axis represents the probability of occurrences on the scale (low probability - high probability). Thegraphs represent the effect of an individual environmental variable on the distribution of the great hornbill $(\mathrm{RH})$ and Rufous-necked hornbill $(\mathrm{RNH})$. Precipitation of wettest month identifies the total precipitation that prevails during the wettest month in $\mathrm{mm}$. The probability of occurrence of $\mathrm{GH}$ and $\mathrm{RNH}$ is high in $800-850 \mathrm{~mm}$ and $450-850 \mathrm{~mm}$ (Fig.4; i \& ii). The range of BIO_13 in the study area is from $79-1181 \mathrm{~mm}$. The probability of occurrence of both GH and RNH is high in slightly higher precipitation of the wettest month. The contribution of Aridity Index in predicting the species presence location for GH and RNH was $19 \%$ and $11.5 \%$ respectively (Fig.4; iii \& iv). The response curve shows that the probability of occurrence of GH is high at 14000 AI (Fig.4; iii), it shows GH prefers humid climatic condition. However, the response curve of RNH shows negative relationship (Fig.4; iv). The probability of occurrences of RNH is high in semi-arid and arid region. The contribution of elevation in predicting the species presence location of GH was highest with $30.4 \%$. The curve shows a negative relationship i.e. elevation increases, the probability of occurrences of species decrease (Fig.4; v) and we can seespecies occurrence probability is high at the elevation below $3000 \mathrm{~m}$. The aspect ranges from 1-360 degree representing the direction between east, west, north and south. The aspect ranging from 340-360 degree is the most suitable for the species which is south-east aspect - (fig. 4; vi). The jackknife test of variable importance shows the highest gain when the variable elevation is used in isolation (Fig. 4 xi \& xii). The environment variable that decreases the gains the most when aspect is omitted in case of RNH and GH

elevation is omitted which indicates that, this variable are most effective to define the model compared to any others (Fig.4 vi \& vii).

Figure 4: Response of GH and RNH to Precipitation of Wettest Month (BIO_13), Aridity 


\section{Index, Elevation}

Finally, the testing average AUC for 100 replicates runs of the model was (AUC $=0.915$ with the standard deviation 0.023) for the great hornbill (Figure 5). And (AUC $=0.872$ with the standard deviation 0.060) for Rufous-necked hornbill (Figure 5).

\section{Figure 5: AUC curve for GH and RNH}

\section{Discussion}

Birds are thought to perform the widest range of ecological functions in the ecosystem (Sekercioglu, 2006). Birds benefit humans by providing a variety of important ecosystem services, including provisioning (food, feathers), regulating (seed dispersal, pollination), cultural (art, religion), and supporting (soil formation, nutrient cycling) services (Millennium Ecosystem Assessment, 2005). Hornbills are frugivore, which means they eat fruit. Frugivores play a critical role in the ecosystem's structure and function (Nathan and MullerLandau, 2000). However, due to the gradually increasing human population following anthropogenic disturbance, there has been a severe decline in the population of these birds.

Species distribution models (SDMs) are widely used in biogeography, biodiversity, and macro-ecology research to model species' geographic distribution based on the correlation between known occurrence records and environmental conditions at occurrence locations (Elith et al., 2011). SDM creates geographic maps of environmental suitability for a species(Raes, 2012). We chose the MaxEnt model to predict the distribution of the Great Hornbill and the Rufous-necked hornbill because its distribution prediction provides a powerful new tool that uses only presence data for species distribution modeling. Since its inception, MaxEnt has grown in popularity (Renner and Warton, 2013). MaxEnt is a presence-only model that allows scientists to tap into the wealth of natural history data while avoiding the high cost of sampling species across their entire range (Phillips et al., 2006). Data on presence is plentiful, but data on absence is difficult to come by and frequently unreliable due to a lack of survey effort (Liu et al., 2013). MaxEnt compares the distribution of presences along environmental gradients to the distribution of background points, which are drawn at random from the study area (Renner and Warton, 2013). Furthermore, it considers interactions between environmental variables and appears to perform reasonably well with small amounts of occurrence data when valid occurrence data and appropriate predictor variables are chosen(Phillips et al., 2006).

The distribution model for the great hornbill and the rufous-necked hornbill was created using 21 environmental variables and three topographical variables (elevation, aspect, and slope). However, after performing a multi-collinearity test in the ENM tool, only thirteen variables were used to prepare a habitat suitability model and conduct further analysis. The results revealed that the most important environmental variables for predicting the species presence location for $\mathrm{GH}$ and $\mathrm{RNH}$ were elevation (30.4\%), precipitation of wettest month (27.2\%), Aridity Index (19\%), and precipitation of wettest month (44.7\%), aspect $(22.3 \%)$, and aridity index (11.5\%), respectively.

The probability of GH occurrence and elevation has a negative relationship, meaning that the likelihood of seeing great hornbills decreases as elevation rises (fig 6\& 7). According to the current study, the probability of GH occurrence is high below 3000 masl. The great hornbill is known to frequent wet evergreen and mixed deciduous forests, ranging out into open deciduous areas to visit fruits and ascend slopes to at least 1,560 masl in south India (Mudappa and Raman, 2009) and up to 2,000 masl in Thailand(Poonswad et al., 2013). The RNH is found in primary subtropical evergreen and deciduous forests between 600 and 2000 masl worldwide but have been seen as high as 2900 masl (Chimchome et al., 1997). RNH presence was predicted in the species occurrences predicted map at Lhuentse, Yangtse, Punakha, and even up to Gasa, which is over 3000 masl. Habitat suitability analysis shows that GH and RNH are highly suitable for 2 and $3 \%$ of the total country's area, respectively. Their occurrence and distribution are affected by factors such as vegetation type, habitat, temperature, availability of food, forest size, and tall old trees with holes(Wagh et al., 2015).

Figure 6: Predicted GH occurrence map from low to high probability values 
Figure 7: Predicted RNH occurrence map from low to high probability values

\section{Conclusion}

The distribution potential of great hornbill and Rufous-necked Hornbill was delineated using species distribution modeling. This model is a very effective tool for mapping the suitable habitats of different species under the influence of topographic and climatic factors. In comparison, Great hornbill has $2 \%$ of the area of Bhutan suitable for habitat whereas Rufous necked hornbill has total of $3 \%$ of most suitable habitat in Bhutan. However Rufous-necked hornbill habitat range is high in central, south-east and north-east region of Bhutan. The probability of occurrence of the great hornbill is high in the southern region and elevation below 3000 msl. Rufous-necked hornbill prefers semi-arid and arid region whereas great hornbill prefers humid condition. The model also revealed that the highest contributing variables for predicting this threatened species were aspect and precipitation of wettest month. The baseline information generated from the present study can be useful facilitating fieldwork, planning and future scientific management of these species in the country.

\section{Data availability statement}

Environmental were obtained from worldClim dataset at a resolution of $1 \mathrm{~km}^{2}$ (http://www.world clim.org). Topograhic variables namely-elevation, aspect, and slope were derived from digital elevation model of Shuttle Radar Topographic Mission (SRTM). The primary data that support the findings of this study are available from the corresponding author upon the request.

\section{References}

Aiyadurai, A., Singh, N.J., Milner-Gulland, E.J., 2010. Wildlife hunting by indigenous tribes: a case study from Arunachal Pradesh, north-east India. Oryx 44, 564-572. https://doi.org/DOI: 10.1017/S0030605309990937

Araujo, M.B., Peterson, A.T., 2012. Uses and misuses of bioclimatic envelope modeling. Ecology 93, 15271539. https://doi.org/https://doi.org/10.1890/11-1930.1

Beale, C.M., Lennon, J.J., 2012. Incorporating uncertainty in predictive species distribution modelling. Philos. Trans. R. Soc. B Biol. Sci. 367, 247-258. https://doi.org/10.1098/rstb.2011.0178

Bennett, E.L., Nyaoi, A.J., Sompud, J., 1997. Hornbills Buceros spp. and culture in northern Borneo: Can they continue to co-exist? Biol. Conserv. 82, 41-46. https://doi.org/https://doi.org/10.1016/S0006$3207(97) 00012-8$

Booth, T.H., 2018. Why understanding the pioneering and continuing contributions of BIOCLIM to species distribution modelling is important. Austral Ecol. 43, 852-860. https://doi.org/https://doi.org/10.1111/aec.12628

Chaisuriyanun, S., Gale, G., Poonswad, P., 2011. FOOD CONSUMED BY GREAT HORNBILL AND RHINOCEROS HORNBILL IN TROPICAL RAINFOREST, BUDO SU-NGAI PADI NATIONAL PARK, THAILAND. Raffles Bull. Zool.

Efremov, Y. V, 2019. Protected Areas and Biodiversity of the Kingdom of Bhutan. Geogr. Nat. Resour. 40, 187-194. https://doi.org/10.1134/S1875372819020124

Franco, F.M., Minggu, M.J., 2019. When the seeds sprout, the hornbills hatch: understanding the traditional ecological knowledge of the Ibans of Brunei Darussalam on hornbills. J. Ethnobiol. Ethnomed. 15, 46. https://doi.org/10.1186/s13002-019-0325-0

Hao, T., Elith, J., Guillera-Arroita, G., Lahoz-Monfort, J.J., 2019. A review of evidence about use and performance of species distribution modelling ensembles like BIOMOD. Divers. Distrib. 25, 839-852. https://doi.org/https://doi.org/10.1111/ddi.12892 
Laurance, W.F., 1999. Reflections on the tropical deforestation crisis. Biol. Conserv. 91, 109-117. https://doi.org/https://doi.org/10.1016/S0006-3207(99)00088-9

LI, X., WANG, Y., 2013. Applying various algorithms for species distribution modelling. Integr. Zool. 8, 124-135. https://doi.org/https://doi.org/10.1111/1749-4877.12000

Lu, C.Y., Gu, W., Dai, A.H., Wei, H.Y., 2012. Assessing habitat suitability based on geographic information system (GIS) and fuzzy: A case study of Schisandra sphenanthera Rehd. et Wils. in Qinling Mountains, China. Ecol. Modell. 242, 105-115. https://doi.org/https://doi.org/10.1016/j.ecolmodel.2012.06.002

Namgyal, J., Lysyk, T.J., Couloigner, I., Checkley, S., Gurung, R.B., Tenzin, T., Dorjee, S., Cork, S.C., 2021. Identification, Distribution, and Habitat Suitability Models of Ixodid Tick Species in Cattle in Eastern Bhutan. Trop. Med. Infect. Dis. . https://doi.org/10.3390/tropicalmed6010027

Nepal, T.K., 2020. Distribution and Threats of Rufous-necked Hornbill (Aceros nipalensis) in Bhutan. Int. J. Sci. Res. 9, 797-800. https://doi.org/10.21275/SR201111231036

Norbu, L., Thinley, P., Wangchuck, T., Dechen, U., Dorji, L., Choephel, T., Dorji, P., 2021. On the high bird diversity in the non-protected regions of Trashiyangtse District in Bhutan. J. Threat. Taxa 13, 19274-19292. https://doi.org/10.11609/jott.6843.13.9.19274-19292

Ouithavon, K., Poonswad, P., Bhumbhakpan, N., Laohajinda, V., 2005. A comparative study of the feeding ecology of two sympatric hornbill species (Aves: Bucerotidae) during their breeding season in Huai Kha Khaeng Wildlife Sanctuary, Thailand. Ecol. Hornbills Reprod. Popul. 59-73.

Pawar, P.Y., Mudappa, D., Raman, T.R.S., 2021. Hornbill abundance and breeding incidence in relation to habitat modification and fig fruit availability. Ibis (Lond. 1859). 163, 473-485. https://doi.org/https://doi.org/10.1111/ibi.12895

Penjor, U., Wangdi, S., Tandin, T., Macdonald, D.W., 2021. Vulnerability of mammal communities to the combined impacts of anthropic land-use and climate change in the Himalayan conservation landscape of Bhutan. Ecol. Indic. 121, 107085. https://doi.org/https://doi.org/10.1016/j.ecolind.2020.107085

Poonswad, P., Chimchome, V., Mahannop, N., Mudsri, S., 2013. Conservation of Hornbills in Thailand. pp. 157-166. https://doi.org/10.1002/9781118679838.ch19

Rajaratnam, R., Vernes, K., Sangay, T., 2016. A Review of Livestock Predation by Large Carnivores in the Himalayan Kingdom of Bhutan. pp. 143-171.

Sherub, K., Singh, A., 2020. Notes on the Food and Feeding habits of Rufous necked Hornbill in Zhemgang district, Bhutan. J. Bombay Nat. Hist. Soc. 117, 50-53. https://doi.org/10.17087/jbnhs/2020/v117/142594

Sherub, K., Tshering, S., 2019. Rapid assessment of two sympatric hornbill in Zhemgang district BirdingAsia 2019. BirdingAsia 54-58.

Shukla, U., Naniwadekar, R., Datta, A., 2016. Abundance estimates of the Rufous-necked hornbill Aceros nepalensis and characterisation of a montane subtropical forest in the Indian Eastern Himalaya. Indian Birds 12.

Singh, H., Kumar, N., Kumar, M., Singh, R., 2020. Modelling habitat suitability of western tragopan (Tragopan melanocephalus) a range-restricted vulnerable bird species of the Himalayan region, in response to climate change. Clim. Risk Manag. 29, 100241. https://doi.org/https://doi.org/10.1016/j.crm.2020.100241

Sun, C.-H., Liu, H.-Y., Zhang, Y., Lu, C.-H., 2019. Comparative analysis of the gut microbiota of hornbill and toucan in captivity. Microbiologyopen 8, e00786. https://doi.org/https://doi.org/10.1002/mbo3.786

Tshewang, U., Morrison, J.G., Tobias, M.C., 2018. National Parks, Protected Areas, and Wildlife Sanctuaries.In Bionomics in the Dragon Kingdom (pp. 17-63). Springer, Cham. 
Warren, D.L., Glor, R.E., Turelli, M., 2010. ENMTools: a toolbox for comparative studies of environmental niche models. Ecography (Cop.). 33, 607-611. https://doi.org/https://doi.org/10.1111/j.16000587.2009.06142.x

WorldClim. (2016). WorldClim Version 2. Retrieved from http://worldclim.org/version2

\section{Hosted file}

List of figures.docx available at https://authorea.com/users/456216/articles/553344-speciesdistribution-modelling-of-two-sympatric-hornbills-the-great-hornbill-and-rufous-neckedhornbill-in-bhutan 